\title{
Surface modification of AZ91 magnesium alloy using GTAW technology
}

\author{
J. IWASZKO ${ }^{1 *}$, M. STRZELECKA ${ }^{1}$, and K. KUDŁA ${ }^{2}$ \\ ${ }^{1}$ Częstochowa University of Technology, Institute of Materials Engineering, 19 Armii Krajowej St., 42-200 Częstochowa, Poland \\ ${ }^{2}$ Częstochowa University of Technology, Department of Welding, 21 Armii Krajowej St., 42-200 Częstochowa, Poland
}

\begin{abstract}
In this study, surface remelting treatment of the AZ91 magnesium alloy by means of welding using a non-consumable electrode in an inert gas shield was carried out. Three variants of surface treatment were used, i.e. the single torch variant with a single heat source without cooling down the samples, the single torch variant with a single heat source and a cooling system with liquid nitrogen, and the double welding torch variant with a double heat source in the torches operating in a tandem configuration. Experimental verification of the applied apparatus solutions was based on both macro- and microstructural assessment of the obtained effects. Comparative analysis of the variants used and the obtained microstructural results allowed the authors to indicate the deficiencies and limitations of particular solutions and to single out the best solution that would be useful for modifying the surface layers of magnesium alloys, as well as other materials having a strong oxygen affinity.
\end{abstract}

Key words: remelting treatment, GTAW technology, AZ91 magnesium alloy.

\section{Introduction}

In the age of increasingly more demanding users and constant improvement of fabrication technologies, the attention of researchers is more frequently focused on shaping the microstructure and properties of a product's surface layer. These activities are fully justified because in many cases the surface layer is decisive regarding the product application potential, its durability and properties [1-3]. Applying a coating or modifying the surface layer allow one to create a material with completely new application potentials and new material characteristics [4-6]. A particularly great potential lies in the technologies that use concentrated heat sources, e.g. laser beam, plasma jet, electron beam or electric arc [7-13]. The efforts to use concentrated heat sources in practice in surface engineering taken at the end of the $20^{\text {th }}$ century determined new directions and trends in the process of forming the surface layers of metals and metal alloys. Numerous technologies and solutions developed at that time were applied in industrial practice, contributing to the competitiveness of the companies that decided to implement innovative technologies. The research and application potential that involves the possibility of using e.g. a laser beam, plasma jet, or electron beam in surface treatment is unquestionable. The changes in the microstructure triggered by the effect of concentrated heat sources may lead to significant improvement of both the mechanical and technological properties of the treated material, and as a result, form a material of completely new functionality and

*e-mail: iwaszko@wip.pcz.pl

Manuscript submitted 2017-01-12, revised 2017-04-03, initially accepted for publication 2017-04-24, published in December 2017. applicability. One of the solutions having a high application potential is the method of surface remelting of magnesium alloys. This treatment is carried out mostly by means of laser technologies [14-19]. To this end, both lasers with continuous operation characteristics and pulse lasers are used. Among the advantages of using the laser beam one can mention is the short time of process execution, the possibility of precise concentration of the beam on a particular surface, as well as obtaining high temperature gradients in the material. The use of methods that are alternative to laser technologies, e.g. conventional welding arc heat sources, is sporadic. Difficulties may occur during the remelting treatment carried out by means of welding methods. Those difficulties are often the effect of the physical and chemical properties of magnesium and magnesium alloys, and particularly their strong oxygen affinity, whose consequence is the presence of a compacted, non-conductive $\mathrm{MgO}$ oxide layer on the material surface. Until recently, welding heat sources were used almost only for joining materials and their regeneration. This situation has been systematically changing in recent years. The GTAW method has been used, among others, by the authors of study [20], who subjected the AK7 aluminium alloy to surface treatment. The favourable microstructural changes triggered by remelting of the alloy resulted in an increase in hardness and resistance to abrasion. In turn, in study [21] iron castings were subjected to GTAW method treatment, and equally satisfactory treatment results were obtained. The GTAW method was used also by D. Wenbin et al. in study [22] to form a composite structure in the surface layer of the AZ31 magnesium alloy.

Within this study assessment of the GTAW method effectiveness in the remelting treatment of the AZ91 magnesium alloy surface layer was conducted, as well as the comparative analysis of various apparatus and parameter variants. 


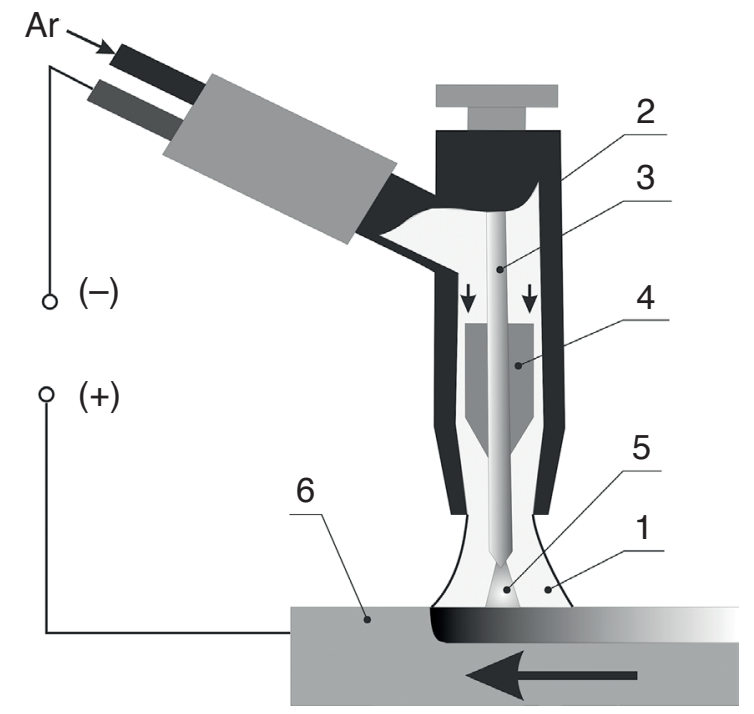

Fig. 1. Model illustrating process of remelting by means of single torch GTAW method: 1 - Shielding gas; 2 - Gas nozzle; 3 - Non-consumable electrode; 4 - Contact tube; 5 - Electric arc; 6 - Material being remelted

\section{Research material}

The research material was the commercially available AZ91 magnesium alloy, obtained by means of the gravity casting method. The chemical composition of the alloy is presented in Table 1 . Cuboid samples measuring $60 \times 30 \times 10 \mathrm{~mm}$ were subject to the remelting treatment with the use of three different apparatus versions: the single torch variant with a single heat source and without any system for cooling the samples down, the single torch variant with a single heat source and a cooling system with liquid nitrogen, and the double welding
Table 1

Chemical composition of AZ91 alloy

\begin{tabular}{|c|c|c|c|c|c|c|c|}
\hline \multirow{2}{*}{ Alloy } & \multicolumn{7}{|c|}{ Element content, wt\% } \\
\cline { 2 - 8 } & $\boldsymbol{A l}$ & $\boldsymbol{Z n}$ & $\boldsymbol{M n}$ & $\boldsymbol{S i}$ & $\boldsymbol{C u}$ & $\boldsymbol{F e}$ & $\boldsymbol{M g}$ \\
\hline AZ91 & 8.5 & 0.7 & 0.32 & 0.01 & 0.001 & 0.001 & rest \\
\hline
\end{tabular}

torch variant with a double heat source in the torches operating in a tandem configuration. Before the remelting process was started, the surface of the samples was cleaned mechanically with 500 gradation abrasive paper and then washed with ethyl alcohol. All the variants of remelting treatment were carried out in an argon atmosphere of the $99.995 \%$ purity ( $\mathrm{Ar} 4.5)$. In both light and scanning electron microscopy studies, the samples in their initial state, and also after the treatment were examined. The light microscopy examinations were performed by means of a Carl Zeiss Jena Axiovert 25 microscope and an Olympus GX41, while the scanning electron examination was carried out by means of a Joel JSM-6610LV electron microscope.

\section{Experimental procedures}

3.1. Single torch variant. The diagram of the single torch variant is presented in Fig. 1. The heat of the electric arc burning between sample 6 and non-consumable electrode 3 was used to remelt the surface layer of the sample. The treatment was carried out by means of a FALTIG-315 AC/DC inverter welding power source with non-consumable tungsten electrodes with an admixture of $\mathrm{ThO}_{2}$, and applied diameters of $2 \mathrm{~mm}$ and $4 \mathrm{~mm}$. Distance "L" between the electrode end and the surfaces of the samples was the same in all the cases and amounted to $2 \mathrm{~mm}$. The flow rate of the shielding gas was fixed at $14 \mathrm{dm}^{3} \cdot \mathrm{min}^{-1}$. The parameters of the remelting process are listed in Table 2. The treatment was carried out with

Table 2

List of exemplary treatment parameters

\begin{tabular}{|c|c|c|c|c|c|c|}
\hline No. & $\begin{array}{l}\text { Current } \\
\text { I, A }\end{array}$ & $\begin{array}{c}\text { Duration of current pulse } \\
\text { and duration of base } \\
\text { t, } s\end{array}$ & $\begin{array}{l}\text { Electrode diameter } \\
\text { d, } \mathbf{m m}\end{array}$ & $\begin{array}{l}\text { Path width } \\
\mathbf{W}_{\mathrm{p}}, \mathbf{m m}\end{array}$ & $\begin{array}{l}\text { Remelting depth } \\
\mathbf{G}_{\mathrm{p}}, \mathbf{m m}\end{array}$ & $\begin{array}{l}\text { Treatment } \\
\text { method }\end{array}$ \\
\hline 1 & $\mathrm{I}=100$ & - & 2 & 10.69 & 2.33 & Manual mode \\
\hline $2^{*}$ & $\begin{array}{l}\mathrm{I}_{\mathrm{i}}=150 \\
\mathrm{I}_{\mathrm{b}}=80\end{array}$ & $\begin{array}{l}\mathrm{t}_{\mathrm{i}}=0.3 \\
\mathrm{t}_{\mathrm{b}}=0.15\end{array}$ & 4 & 8.55 & $\begin{array}{l}\text { measurement } \\
\text { given up }\end{array}$ & \multirow{4}{*}{ 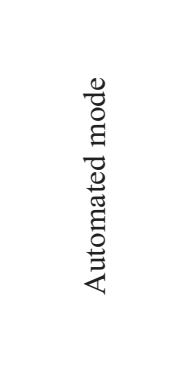 } \\
\hline $3^{*}$ & $\begin{array}{l}\mathrm{I}_{\mathrm{i}}=130 \\
\mathrm{I}_{\mathrm{b}}=90\end{array}$ & $\begin{array}{l}\mathrm{t}_{\mathrm{i}}=0.3 \\
\mathrm{t}_{\mathrm{b}}=0.15\end{array}$ & 4 & 6.90 & 1.29 & \\
\hline 4 & $\begin{array}{l}\mathrm{I}_{\mathrm{i}}=90 \\
\mathrm{I}_{\mathrm{b}}=51\end{array}$ & $\begin{array}{l}\mathrm{t}_{\mathrm{i}}=0.2 \\
\mathrm{t}_{\mathrm{b}}=0.2\end{array}$ & 2 & 9.47 & 2.92 & \\
\hline 5 & $\mathrm{I}_{\mathrm{b}}=74$ & - & 2 & 7.94 & 2.02 & \\
\hline
\end{tabular}

I - welding current, $I_{i}-$ pulse current, $I_{b}-$ base current, $t_{i}-$ current pulse duration, $t_{b}-$ base duration

*Unsatisfactory macroscopic effects of treatment 
$\mathrm{AC}$ (alternating current), but tests were also performed with other kinds of current and their polarity. AC is of course most frequently used to weld light metal alloys such as aluminium alloys or magnesium alloys. Unfortunately, the application of $\mathrm{AC}$ with only one heat source to remelt the surface layer of magnesium alloys within the range of low and medium currents does not produce satisfactory results. Therefore, the scope of the studies included the application of various polarities and current types (AC, DC+, DC-), both with a constant and pulsating current, with simultaneous removal of oxides by mechanical or cathodic cleaning (in the case of $\mathrm{AC}$ and of unidirectional current with positive polarity $\mathrm{DC}+$ ) and by their combination. Unfortunately, the use of AC with a negative polarity (with previous mechanical removal of the $\mathrm{MgO}$ oxide) caused high instability of the arc, whereas the use of DC with a positive polarity led to fast heating up of the electrode that made it impossible to apply higher current values indispensable to obtain the effect of remelting of the surface layer. The use of AC allowed the authors to avoid those problems and made it possible to conduct the process of cathodic cleaning leading to breaking of the surface oxide layer and remelting of the magnesium alloy surface layer. In the experiment, the constant linear speed of the welding torch amounting to $8.2 \mathrm{~mm} \cdot \mathrm{s}^{-1}$ was used. The treatment was carried out in both manual and automated remelting modes. The most favourable changes in macroscopic terms were observed with the use of AC without pulsation of the intensity of $100 \mathrm{~A}$ (for the manual mode) and $74 \mathrm{~A}$ (for the automated one). When it comes to the pulsed current, the best remelting effects were obtained when the pulse current of $90 \mathrm{~A}$ and the base current of $51 \mathrm{~A}$ were used. Regarding other current values listed in Table 2, unfavourable changes in the surface geometry of the tested material were observed. However, the use of AC did not always guaranteed repeatability of the remelting effects. This could have been caused by the varying thickness of the oxide layer in various places of the surface being modified, leading to uneven remelting of the material. This effect occurred particularly in the samples that were subject to automated remelting. In case of the manual remelting mode, the operator has the possibility to adjust the remelting parameters (e.g. the linear speed of the welding torch, the distance between the electrode and the surface, hence the length of the electric arc) and in this way to obtain the intended remelting effect. Extending the interaction time of the electric arc and the sample surfaces, enabling remelting of both the magnesium alloy and the oxide layer, as a rule, led to considerable loss of the material within the remelted path, and even to deformation of the sample. In turn, an increase in the cathodic cleaning current resulting in improvement of the effectiveness of oxide removal, reduced the thermal emission strength of the non-consumable electrode, contributing to its faster consumption. These problems show the difficulty of selecting the treatment parameters and the helpfulness of prior mechanical and/or chemical removal of the oxide layer from the material surface. Due to the high affinity of magnesium alloy for oxygen, the time between the oxide removal and the remelting treatment to be performed is also vital. That time shall obviously be as short as possible.

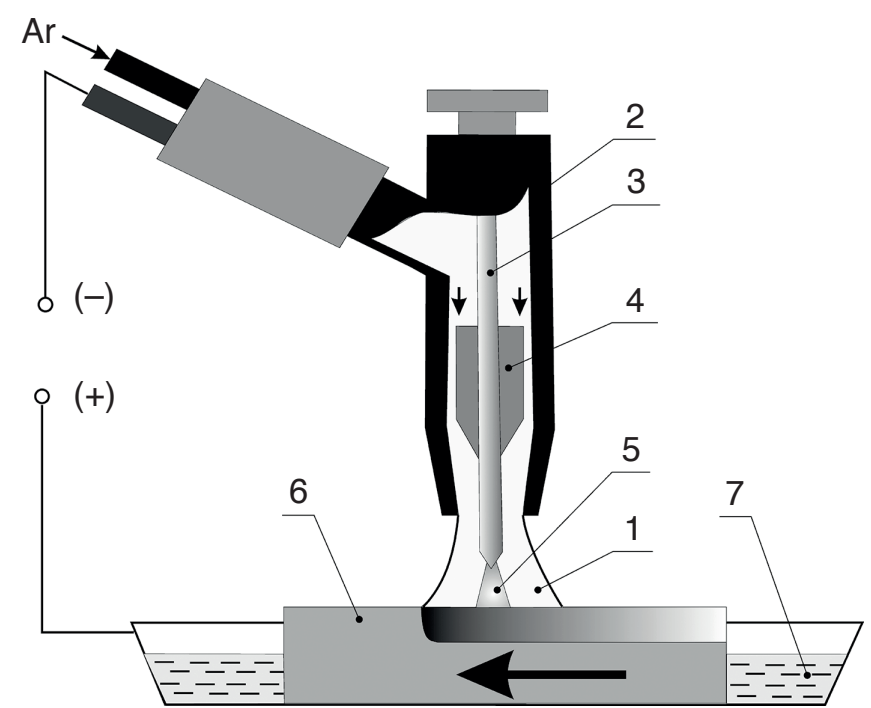

Fig. 2. Graphical model of station for remelting using cooling down system: 1 - Shielding gas; 2 - Gas nozzle; 3 - Tungsten electrode; 4 - Contact tube; 5 - Electric arc; 6 - Material being remelted; 7 - Cooling system with liquid nitrogen

3.2. Single torch variant with cooling system. An increase in the rate of cooling down the remelting zone gives a possibility to obtain greater structure refinement, and as a result, improvement of the mechanical properties of the remelted zone in comparison with its non-remelted equivalents or the ones remelted without a cooling factor. Keeping this in mind, an effort to conduct the remelting treatment in conditions of faster cooling of the material was taken. To this end, cooling down by means of liquid nitrogen was applied. A diagram of the applied solution is shown in Fig. 2. In the developed solution, the electric arc burns between the electrode and the sample being remelted and placed on the conductive metallic base. The cryogenic bathtub, along with a sample immersed in it, constituted one pole of the system, and the second pole was the tungsten electrode. After every remelting treatment liquid nitrogen was added to the bathtub to obtain uniform cooling conditions for all the samples. Due to the physical and chemical properties of the material being remelted, and particularly its susceptibility to oxidation, the treatment was carried out with the use of a torch powered by AC, which, at the same time, allowed for cathodic cleaning of the material from oxides and remelting of the surface layer of the magnesium alloy. A detailed description of the developed solution can be found in study [23].

In the experiment a Master TIG (MLS 2300 AC/DC) inverter welding power source was used. The treatment was performed by applying AC with the use of non-consumable tungsten electrodes with an admixture of $\mathrm{ThO}_{2}$. Electrodes $2.4 \mathrm{~mm}$ and $4 \mathrm{~mm}$ in diameter of were used, and the "L" distance from the electrode to the sample surface was $2 \mathrm{~mm}$. Only the manual mode remelting variant was used in the experiment. Detailed characteristics of the adopted remelting parameters are pre- 
Table 3

List of exemplary remelting parameters by means of GTAW method with cooling system

\begin{tabular}{|l|c|c|c|c|c|c|}
\hline No. & $\begin{array}{c}\text { Welding current } \\
\mathbf{I}, \mathbf{A}\end{array}$ & $\begin{array}{c}\text { Current frequency } \\
\mathbf{f}, \mathbf{~ H z}\end{array}$ & $\begin{array}{c}\text { Linear speed } \\
\text { of welding torch } \\
\mathbf{V}, \mathbf{m m} \cdot \mathbf{s}^{-\mathbf{1}}\end{array}$ & $\begin{array}{c}\text { Electrode diameter } \\
\mathbf{d}, \mathbf{m m}\end{array}$ & $\begin{array}{c}\text { Path width } \\
\mathbf{W}_{\mathbf{p}}, \mathbf{m m}\end{array}$ & $\begin{array}{c}\text { Remelting depth } \\
\mathbf{G}_{\mathbf{p}}, \mathbf{m m}\end{array}$ \\
\hline 1 & 125 & 5 & 5 & 2.4 & 9.36 & 2.16 \\
\hline 2 & 125 & 150 & 5 & 2.4 & 8.26 & 1.68 \\
\hline 3 & 125 & 250 & 5 & 2.4 & 8.14 & 1.37 \\
\hline 4 & 175 & 50 & 5 & 4 & 10.12 & 2.30 \\
\hline $5^{*}$ & 225 & 50 & 8.5 & 4 & 10.72 & 2.55 \\
\hline
\end{tabular}

*Unsatisfactory macroscopic effects of treatment

sented in Table 3. The treatment was carried out using the two main parameters: the welding current and its frequency. A major limitation is the overheating of magnesium alloys when using high currents in their remelting. Therefore, in order to be able to run the process at higher current values, intensive cooling of the material being remelted by means of liquid nitrogen was applied. AC of a constant frequency was used, which ranged between 50 and $250 \mathrm{~Hz}$. An increase in frequency at the same current led to narrowing of the arc and a narrower remelting zone with deeper fusion. Better fusion and the possibility of removing surface oxides were obtained without overheating of the material occurring and the need to apply an additional pulsating current arc.

The linear speeds of the welding torch were $5 \mathrm{~mm} \cdot \mathrm{s}^{-1}$ and $8.5 \mathrm{~mm} \cdot \mathrm{s}^{-1}$. The flow rate of the shielding gas was fixed at the level of $14 \mathrm{dm}^{3} \cdot \mathrm{min}^{-1}$. The remelting process was implemented with the use of the welding current of $125 \mathrm{~A}$ up to $225 \mathrm{~A}$. An increase in the current led to an increase in the dimensions of the remelting zone, but at the same time, an increase in the risk of the occurrence of unfavorable changes in the geometric structure of the surface. Such disqualifying changes in the surface geometry were observed for the $\mathrm{I}=225$ A current, in spite of using a high linear speed of welding torch rate amounting to $8.5 \mathrm{~mm} \cdot \mathrm{s}^{-1}$.

On the basis of the research it was also revealed that an increase in the welding current frequency at its constant intensity leads to a reduction in the remelted zone dimensions. It resulted from a change in the heat source geometry and its narrowing in the remelting zone, which was caused by a reduction in the impact of the current amplitude phases for the increasing frequencies, in order to maintain a constant, unchanged current level.

3.3. Double welding torch variant. A diagram of the double welding torch variant is presented in Fig. 3. The essence of the developed solution was a system with two independent torches operating in a tandem configuration. In the course of the treatment, the electric arc of the alternating current burning between non-consumable electrode 5 of torch $\boldsymbol{A}$ and the material surface caused breaking of the oxide layer on the surface of the material being modified and initial heating up of the surface layer, whereas the heat of the arc burning between non-consumable electrode 6 of torch $\boldsymbol{B}$ enabled intensive remelting of the surface layer of the material cleaned from a thin layer of oxides by torch $\boldsymbol{A}$ to the required depth. Therefore, the function of leading torch $\boldsymbol{A}$ was to remove the layer of the oxides by means of cathodic cleaning, while the function of the torch following torch $\boldsymbol{A}$ was to remelt the surface cleaned this way. In the developed system, the cleaning torch $\boldsymbol{A}$ was powered by AC, and remelting torch $\boldsymbol{B}$ was connected with the power pack of a one-direction pulsating current. The use of the one-direction pulsating current, consisting in pulsating introduction of electric arc heat through cyclically repeated welding current pulses, enabled the authors to achieve the main experiment purpose, i.e. to obtain favorable structural changes in the surface layer of the AZ91 magnesium alloy without triggering any disqualifying changes in the surface geometry. Moreover, the proposed double welding torch solution eliminated the need for mechanical and/or chemical removal of the oxide layer from the surface of the magnesium alloy being remelted before the remelting process. The double welding torch variant is described in detail in study [24].

The surface treatment performed by means of the double torch GTAW method was carried out by means of two inverter welding power sources: FALTIG-315 AC/DC and FALTIG-200 DC with the use of tungsten non-consumable electrodes with an admixture of $\mathrm{ThO}_{2}$ and diameters of $2.4 \mathrm{~mm}$ and $4 \mathrm{~mm}$.

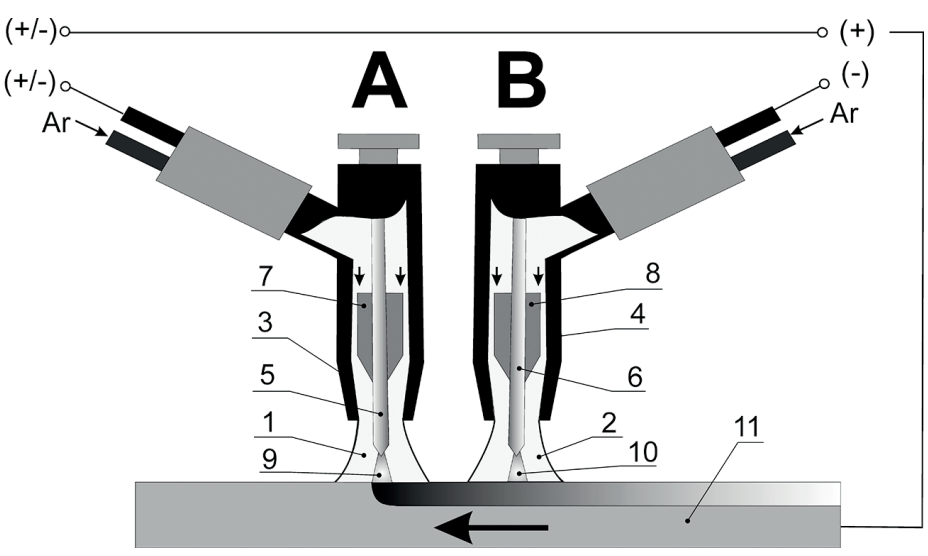

Fig. 3. Graphical model of double welding torch system: 1, 2 - Shielding gas; 3, 4- Gas nozzles; 5, 6 - Non-consumable electrodes; 7, 8 - Contact tube; 9,10-Electric arc; 11 - Material being remelted 
Table 4

List of exemplary treatment parameters by means of double welding torch variant

\begin{tabular}{|c|c|c|c|c|c|c|}
\hline No. & $\begin{array}{c}\text { Current in torch } \mathbf{A} \\
\mathbf{I}_{\mathbf{A}}, \mathbf{A}\end{array}$ & $\begin{array}{c}\text { Current in torch B } \\
\mathbf{I}_{\mathbf{B}}, \mathbf{A}\end{array}$ & $\begin{array}{c}\text { Linear speed } \\
\text { of torches } \mathbf{A} \text { and } \mathbf{B} \\
\mathbf{V}, \mathbf{m m} \cdot \mathbf{s}^{-\mathbf{1}}\end{array}$ & $\begin{array}{c}\text { Electrode diameter } \\
\mathbf{d}, \mathbf{m m}\end{array}$ & $\begin{array}{c}\text { Path width } \\
\mathbf{W}_{\mathbf{p}}, \mathbf{m m}\end{array}$ & $\begin{array}{c}\text { Remelting depth } \\
\mathbf{G}_{\mathbf{p}}, \mathbf{m m}\end{array}$ \\
\hline 1 & 98 & 80 & 5 & 2.4 & 6.70 & 1.45 \\
\hline 2 & 98 & 100 & 5 & 2.4 & 6.81 & 2.13 \\
\hline 3 & 98 & 110 & 5 & 2.4 & 8.50 & 2.68 \\
\hline $4^{*}$ & 98 & 120 & 5 & 4 & 7.09 & 2.73 \\
\hline $5^{*}$ & 98 & 150 & 5 & 4 & 7.65 & measurement given up \\
\hline $6^{*}$ & 98 & 150 & 8.5 & 4 & 6.30 & measurement given up \\
\hline
\end{tabular}

*Unsatisfactory macroscopic effects of treatment

The experiment included the following constant remelting parameters: the distance between the electrode and the sample surface (amounting to $2 \mathrm{~mm}$ ) and the current in the cleaning torch $(98 \mathrm{~A})$. The applied current in the remelting torch varied (within the range of 80 up to $150 \mathrm{~A}$ ) as well as the linear speed of the welding torch (from $5 \mathrm{~mm} \cdot \mathrm{s}^{-1}$ up to $8.5 \mathrm{~mm} \cdot \mathrm{s}^{-1}$ ). The distance between the two torches was set at about $25-30 \mathrm{~mm}$ and the flow rate of the shielding gas was set at the level of $14 \mathrm{dm}^{3} \cdot \mathrm{min}^{-1}$. The AZ91 alloy remelting parameters by means of the double welding torch solution are listed in Table 4.

Analysis of the remelting effects versus the treatment parameters showed that the most favorable structural changes in both macro - and microstructural terms took place in the samples remelted using a current amounting to $80 \mathrm{~A}$ up to $110 \mathrm{~A}$ in the remelting torch, and the $\mathrm{V}$ linear speed of the welding torch rate of $5 \mathrm{~mm} \cdot \mathrm{s}^{-1}$. An increase in the current led to the occurrence of visible losses in the material and unfavorable changes in the surface geometry, while an increase in the linear speed of the welding torch from 5 to $8.5 \mathrm{~mm} \cdot \mathrm{s}^{-1}$ resulted in the presence of strong surface waviness.

(a)

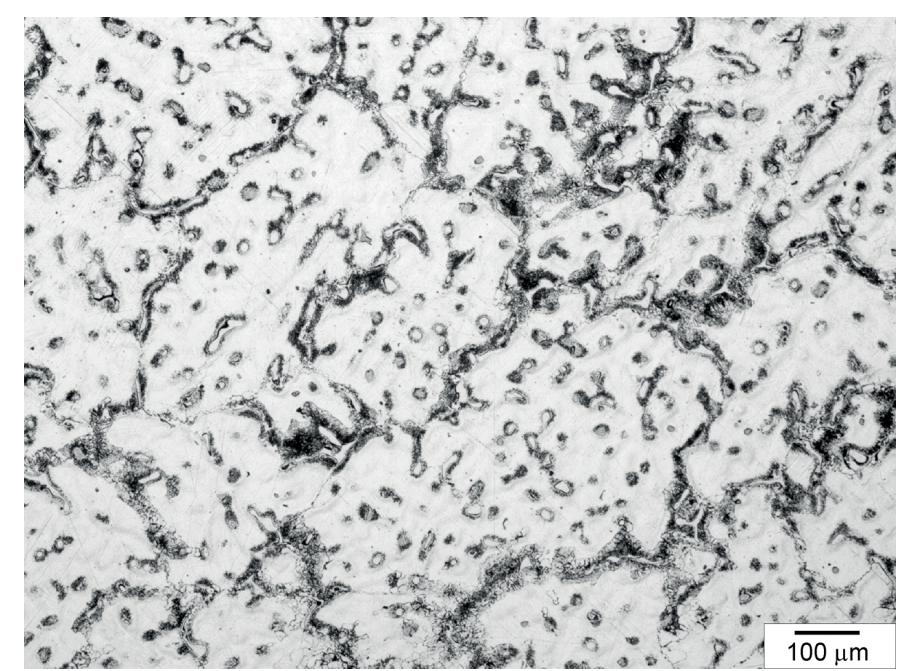

\section{Microstructural investigations}

An exemplary microstructure of the AZ91 alloy in its initial condition is presented in Fig. 4. The presence of solid solution $\alpha, \alpha+\gamma$ eutectics $\left(\gamma-\right.$ intermetallic compound $\left.\mathrm{Mg}_{17} \mathrm{Al}_{12}\right)$, and secondary precipitation of the $\gamma$ phase with characteristic lamellar morphology in the alloy structure was found.

In the samples remelted by means of the GTAW method (in both the single and double welding torch variants) the presence of a clearly formed remelted zone was found, followed by a partially remelted zone. The occurrence of a similar partially remelted zone was observed by, among others, the authors of studies [25-27], and they explain its presence by the specificity of magnesium alloys, and particularly by the low fusion temperature of the eutectics $(710 \mathrm{~K})$ as well as the precipitation of the $\gamma$ phase (about $723 \mathrm{~K}$ ).

In the course of the remelting process, the temperature in the material directly adjacent to the area being remelted exceeds the temperature of the eutectic transformation and the melting point of the interdendritic precipitations, thereby favouring the for-

Fig. 4. Microstructure of AZ91 alloy in its initial condition, etched cross-section, a) light microscopy, b) scanning electron microscopy 
mation of a partially remelted zone. The heat conductivity and capacity of the magnesium alloy, as well as the rate of cooling the layer being remelted, are decisive for the temperature distribution in the material. This, in turn, is decisive for the thickness of the partially remelted zone. In the layers remelted by means of the GTAW method (for both the single and double welding torch variants) strong refinement of the structure and a more even layout of the phases were observed. Despite the methodological differences between the individual treatment versions and various remelting parameters, a comparable degree of structure refinement was obtained. Therefore, it can be stated that the additional cooling used in the single torch variant did not affect the refinement of the structure to the extent that was expected.

Structure refinement and a more even layout of the phases were the main components of the changes triggered by the remelting process. Regardless of the treatment version used, the presence of fine dendrites of the $\alpha-\mathrm{Mg}$ phase and $\gamma$ phase in the interdendritic spaces was noticed in the structure of the surface layers. The size and character of the microstructural changes occurring in the samples being remelted with the use of the single torch and double torch GTAW methods are shown in detail in Figs 5 and 6 . The extent of structure refinement in the layers remelted by the double torch GTAW method depending on the current in the remelting torch is presented in Figs $7 \mathrm{a}$ and $7 \mathrm{~b}$. The microstructural changes observed in the samples remelted with the use of both the single and double welding torch variants were of similar character.

Changes in the microstructure of the remelted samples caused a significant increase in the hardness and wear resistance of the magnesium alloy samples. The hardness of the remelted layers increased by about $50-60 \%$. The average hardness of the non-remelted AZ91 alloy was 58 HV0.05. The hardness of the remelted zone was similar in all the treatment variants, and ranged from 68 up to $93 \mathrm{HV} 0.05$. The increase in wear resistance manifested itself in a significantly lower mass loss during the test in relation to untreated samples. The friction coefficients
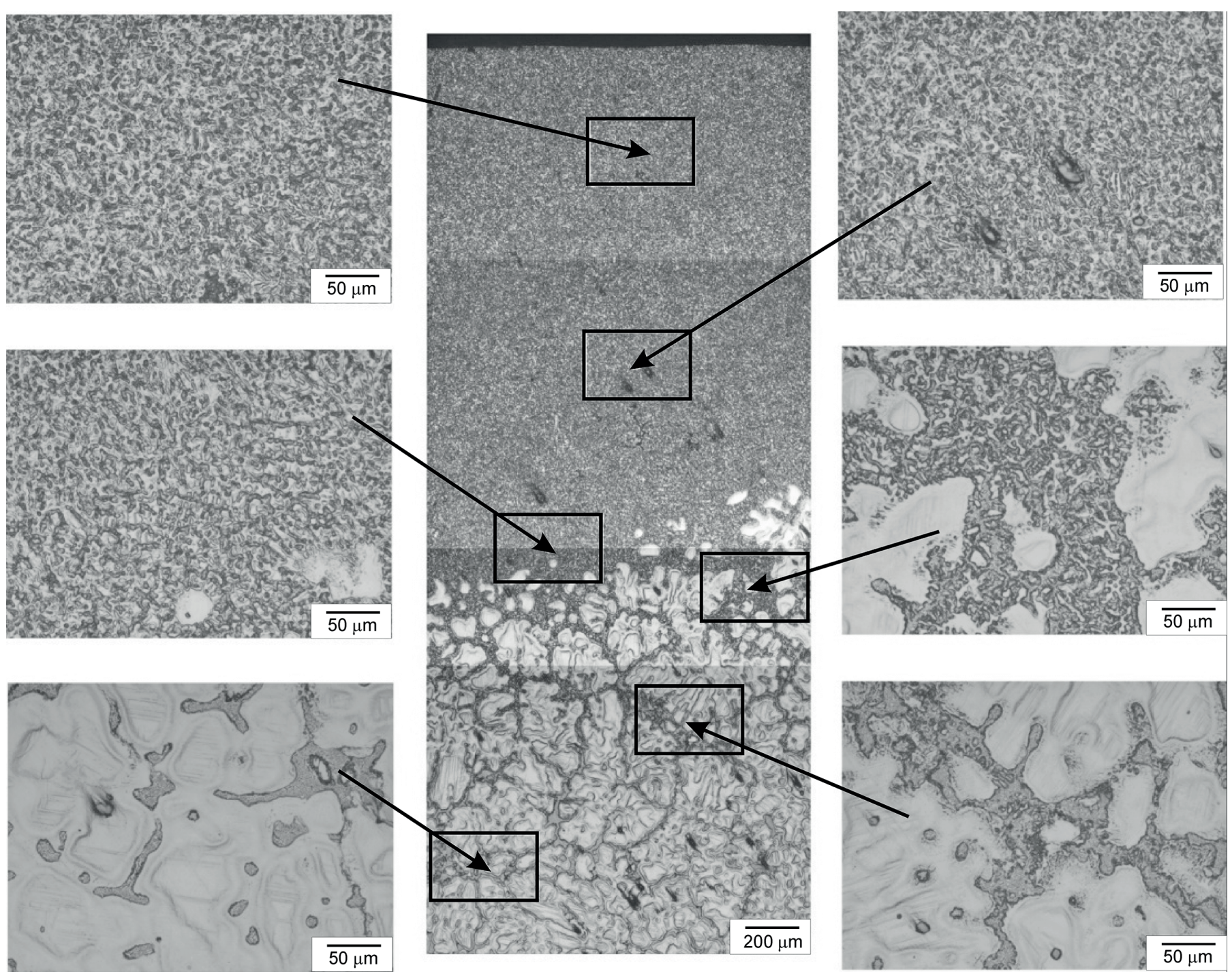

Fig. 5. Structure and morphology of layer remelted by double torch GTAW method with current $\mathrm{I}=98 \mathrm{~A}$ in cleaning torch, and current in remelting torch $\mathrm{I}=100 \mathrm{~A}$, etched transverse micro-sections, light microscopy 


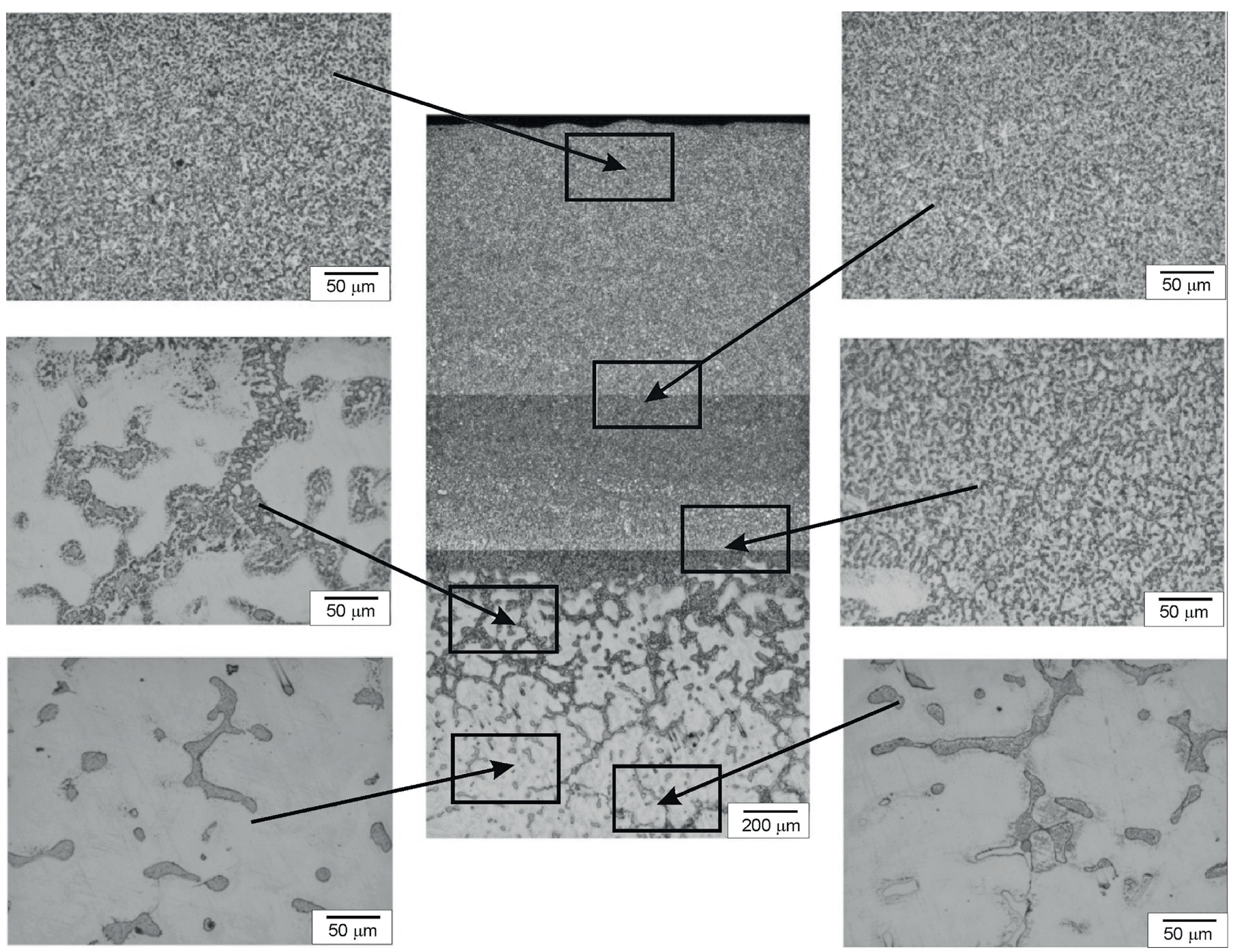

Fig. 6. Structure and morphology of layer remelted by single torch GTAW method with current I $=98 \mathrm{~A}$, and current frequency $\mathrm{f}=50 \mathrm{~Hz}$, etched transverse micro-sections, light microscopy

(a)

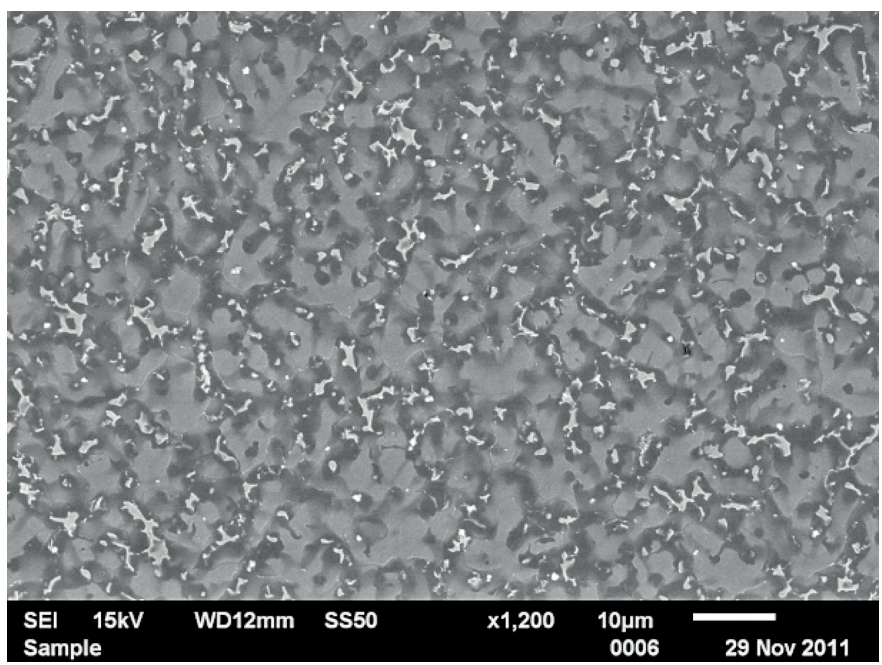

(b)

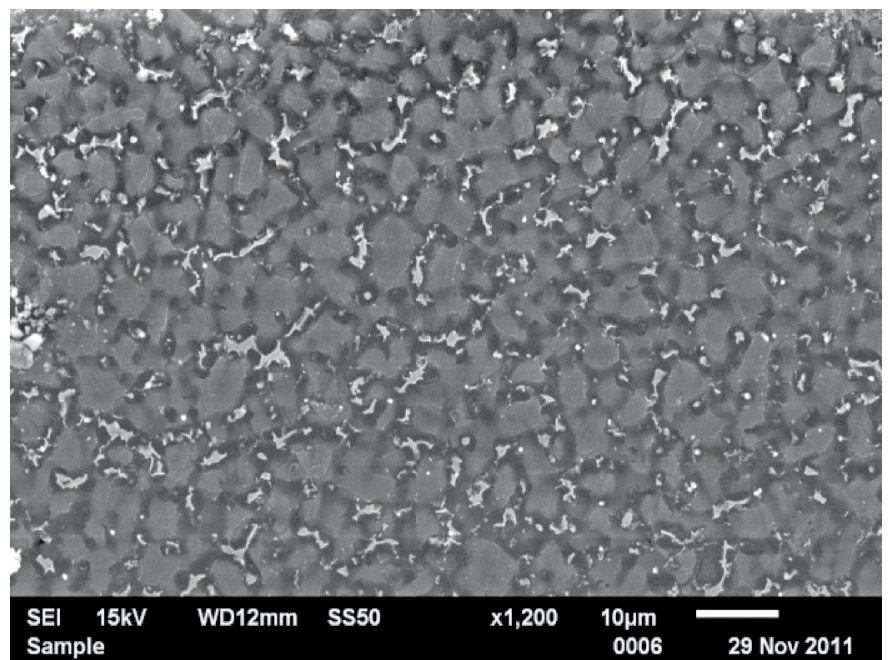

Fig. 7. Microstructures of layers remelted by double torch variant with current in cleaning torch $\mathrm{I}=98 \mathrm{~A}$, and current in remelting torch: a) $\mathrm{I}=100 \mathrm{~A}$, and b) $\mathrm{I}=110 \mathrm{~A}$, etched transverse micro-sections, scanning electron microscopy 
for the AZ91 alloy after remelting were 0.335 and 0.334 for the single torch variant and double torch variant respectively, whereas for the untreated material this coefficient was 0.375 . Detailed results of the hardness and wear resistance tests are presented in paper [23].

\section{Comparative analysis of used variants of remelting with GTAW technology}

Table 5 presents a list of the advantages and limitations of the individual variants observed during the treatment. The tests carried out showed that the use of the single torch GTAW variant provides, to the smallest extent, repeatability of the remelting effects, particularly when there is no possibility to conduct cathodic cleaning. Moreover the changes in the geometrical structure of the surface disqualified the treatment in many cases. In addition, as for the single torch method, it was particularly important to thoroughly mechanically or chemically remove the oxide layer from the surface before remelting. The time between this operation and the remelting treatment was also important. A serious drawback of this solution was also the lack of repeatability of the remelting effects, regardless of the type of power source. The double welding torch solution enabled the authors to eliminate a number of those drawbacks and limitations. The greatest advantage of the double welding torch variant was the possibility to limit and even eliminate the need for previous removal of the oxide layer from the alloy surface.
What is more, for the double welding torch method, the highest repeatability of the treatment effects obtained should be attributed to the high effectiveness of this method in removing the oxide layer, and by this, eliminating the possible impact of the varying thickness of that layer on the remelting effects. In every treatment version used, the most important issue was proper selection of the remelting parameters. This is because appropriate selection of these parameters allows one to limit unfavourable changes in the material surface geometry.

Regarding remelting by the single and double welding torch methods, small differences in the extent of structure refinement of the samples remelted using a similar current and linear speed of the welding torch rate parameters were observed. However, the treatment with simultaneous cooling down of the samples in the liquid nitrogen bath enabled the authors to remove the effect of heating up the sample during remelting, which is particularly important when conducting a multi-path remelting process, and in those terms, one can say that this version prevails over the other solutions such as remelting without additional cooling or cooling on a copper plate.

\section{Summary}

Remelting of the surface layer of magnesium alloys involves the need to overcome the difficulties resulting from the strong affinity of magnesium for oxygen. The $\mathrm{MgO}$ oxide layer present on the magnesium alloy surface is a barrier limiting the process

Table 5

Comparison of individual remelting variants

\begin{tabular}{|c|c|c|}
\hline Variant & Type of current & Drawbacks and advantages of method \\
\hline \multirow{3}{*}{ Single torch variant } & DC with positive polarity & $\begin{array}{l}\text { (+) possibility of cathodic cleaning of surface } \\
(-) \text { fast heating up of electrode } \\
(-) \text { limited range of current values } \\
(-) \text { lack of repeatability of remelting effects }\end{array}$ \\
\hline & DC with negative polarity & $\begin{array}{l}\text { (-) high arc instability } \\
(-) \text { necessity to previously remove oxides from surface } \\
(-) \text { lack of repeatability of remelting effects }\end{array}$ \\
\hline & $\mathrm{AC}$ with and without pulsation & $\begin{array}{l}\text { (+) possibility of cathodic cleaning of surface } \\
(+) \text { wide current range } \\
(-) \text { irregularity of remelting caused by heterogeneous thickness of oxide layer } \\
\text { (-) necessity to previously remove oxides from surface } \\
(-) \text { lack of repeatability of remelting effects }\end{array}$ \\
\hline $\begin{array}{l}\text { Single torch variant } \\
\text { with cooling system }\end{array}$ & AC without pulsation & $\begin{array}{l}(+) \text { possibility of cathodic cleaning of surface } \\
(+) \text { possibility to obtain better structure refinement } \\
(+) \text { possibility of fast cooling down of sample; it is particularly important for } \\
\text { multi-path remelting } \\
(-) \text { the need to constantly add liquid nitrogen to cryogenic bathtub } \\
(-) \text { recommended earlier removal of oxide layer from surface }\end{array}$ \\
\hline $\begin{array}{l}\text { Double welding } \\
\text { torch variant }\end{array}$ & $\begin{array}{l}\text { AC without pulsation in cleaning } \\
\text { torch and one-direction pulsed } \\
\text { current in remelting torch }\end{array}$ & $\begin{array}{l}(+) \text { possibility of conducting treatment without need for prior mechanical or } \\
\text { chemical cleaning of material surface } \\
(+) \text { cathodic cleaning of sample surface is integrated with remelting process } \\
(+) \text { highest repeatability of remelting effects of all treatment variants }\end{array}$ \\
\hline
\end{tabular}

$(+)$ advantage $(-)$ drawback 
of arc remelting of the surface layer. Oxides are an obstacle for current flow, triggering deflection of the electric arc, and their high temperature, several times higher than the melting point of magnesium alloy, strongly disrupts the remelting process and significantly limits the possibility of effective modification of the surface layer of magnesium alloy. Furthemore, the treatment is accompanied by unfavourable changes in the geometrical structure of the material being remelted that in many cases disqualify the adopted remelting method. Remelting the surface layer of the AZ91 magnesium alloy and overcoming both thermal and electrical barriers in the form of surface oxides are possible after applying an AC current as the heat source for remelting. It is feasible due to cathodic cleaning of the magnesium alloy surface by $\mathrm{AC}$ resulting in breaking of the oxide surface layer. However, the varying thickness of the oxide layer may be the reason for the uneven cathodic cleaning of the surface. This problem can be overcome by using the double welding torch remelting variant consisting of two independent torches operating in a tandem configuration, the first of which, powered by $\mathrm{AC}$, removes the oxide layer by means of the cathodic cleaning phenomenon and initially heats up the surface layer, and the second torch, powered by DC pulsed current, remelts to the required depth of the surface stripped of the oxide layer. Thanks to integration of the remelting process with the surface cleaning operation, there is a possibility to limit and even completely eliminate the need for mechanical and/or chemical removal of the oxide layer from the material surface. Therefore, the advantage of the double welding torch variant is obvious.

\section{Conclusions}

Based on the conducted investigations and analysis of the obtained results, the following statements and conclusions have been formulated:

1. The double torch GTAW unit with two heat sources in the torches operating in a tandem configuration provides the possibility to remove the oxide layer by means of cathodic cleaning, and simultaneous remelting of the material surface layer without the need for previous mechanical or chemical cleaning of the surface.

2. The treatment with simultaneous cooling down of the material being remelted in a liquid nitrogen bath eliminates the effect of heating up of the samples accompanying the process of remelting; this is particularly important for multi-path remelting, however, it affects the degree of structure refinement to a small extent.

3. Remelting of the surface layer of magnesium alloys by means of GTAW technology can be an alternative, competing solution when compared with laser technologies.

\section{REFERENCES}

[1] I.D. Utu, G. Marginean, I. Hulka, V.A. Serban, and D. Cristea, "Properties of the thermally sprayed $\mathrm{Al}_{2} \mathrm{O}_{3}-\mathrm{TiO}_{2}$ coatings deposited on titanium substrate", Int. Journal of Refractory Metals and Hard Materials 51, 118-123 (2015).
[2] F. Zhang, C. Zhang, R. Zeng, L. Song, L. Guo, and X. Huang, "Corrosion resistance of the superhydrophobic $\mathrm{Mg}(\mathrm{OH})_{2} / \mathrm{Mg}-\mathrm{Al}$ layered double hydroxide coatings on magnesium alloys", Metals 6 (4), (2016).

[3] M. Gwoździk, "Characteristic of crystallite sizes and lattice deformations changes in the oxide layer formed on steel operated for a long time at an elevated temperature", Solid State Phenomena 203-204, 204-207 (2013).

[4] T. Chmielewski, D. Golański, and W. Włosiński, "Metallization of ceramic materials based on the kinetic energy of detonation waves", Bull. Pol. Ac.: Tech. 63 (2), 449-456 (2015).

[5] J. Iwaszko and K. Kudła, "Surface modification of $\mathrm{ZrO}_{2}-10$ wt. \% CaO plasma sprayed coating", Bull. Pol. Ac.: Tech. 64 (4), 937-942 (2016).

[6] I. Mitelea, I. Bordeasu, I.D. Utu, and O. Karancsi, "Improvement of the cavitation erosion resistance of titanium alloys deposited by plasma spraying and remelted by laser", Materiale Plastice 53 (1), 29-33 (2016).

[7] Q.-Y. Wang, S.-L. Bai, Y.-F. Zhang, and Z.-D. Liu, "Improvement of Ni-Cr-Mo coating performance by laser cladding combined re-melting", Applied Surface Science 308, 285-292 (2014).

[8] H.L. Tian, S.C. Wei, Y.X. Chen, H. Tong, Y. Liu, and B.S. Xu, "Surface remelting treated high velocity arc sprayed FeNiCrAlBRE coating by Tungsten Inert Gas", Physics Procedia 50, 322-327 (2013).

[9] J. Sure, A.R. Shankar, and U.K.Mudali, "Surface modification of plasma sprayed $\mathrm{Al}_{2} \mathrm{O}_{3}-40 \mathrm{wt} \% \mathrm{TiO}_{2}$ coatings by pulsed ND:YAG laser melting", Optics and Laser Technology 48, 366-374 (2013).

[10] I. Watanabe, M. McBridge, P. Newton, and K.S. Kurtz, "Laser surface treatment to improve mechanical properties of cast titanium", Dental Materials 25, 629-633 (2009).

[11] A. Wrońska and A. Dudek, "Characteristics of surface layer of sintered stainless steels after remelting using GTAW method", Archives of Civil and Mechanical Engineering 14 (3), 425-432 (2014).

[12] M. Szkodo, A. Bień, and M. Antoszkiewicz, "Effect of plasma sprayed and laser re-melted $\mathrm{Al}_{2} \mathrm{O}_{3}$ coatings on hardness and wear properties of stainless steel", Ceramics International 42 (9), 11275-11284 (2016).

[13] J. Kusinski, S. Kac, A. Kopia, A. Radziszewska, M. Rozmus-Górnikowska, B. Major, L. Major, J. Marczak, and A. Lisiecki, "Laser modification of the materials surface layer - a review paper”, Bull. Pol. Ac.: Tech. 60 (4), 711-728 (2012).

[14] A.K. Mondal, S. Kumar, C. Blawert, and N.B. Dahotre, "Effect of laser surface treatment on corrosion and wear resistance of ACM720 Mg alloy", Surface and Coatings Technology 202, 3187-3198 (2008).

[15] Y. Jun, G.P. Sun, and S.S. Jia, "Characterization and wear resistance of laser surface melting AZ91D alloy", Journal of Alloys and Compounds 455, 142-147 (2008).

[16] J. Iwaszko and M. Strzelecka, "Effect of $\mathrm{cw}-\mathrm{CO}_{2}$ laser surface treatment on structure and properties of AZ91 magnesium alloy", Optics and Lasers in Engineering 81, 63-69 (2016).

[17] Z. Zhang, P. Lin, and L. Ren, "Wear resistance of AZ91D magnesium alloy processed by improved laser surface remelting", Optics and Lasers in Engineering 55, 237-242 (2014).

[18] M. Strzelecka, J. Iwaszko, and M.A. Malik, "Corrosion resistance of AZ91 magnesium alloy after laser remelting treatment", Journal of Wuhan University of Technology-Mater. Sci. Ed. 31 (5), 1075-1080 (2016). 
[19] J. Zhou, J. Xu, S. Huang, and X. Feng, "Effect of laser surface melting with alternating magnetic field on wear and corrosion resistance of magnesium alloy", Surface and Coatings Technology 309 (15), 212-219 (2017).

[20] A.W. Orłowicz and M. Mróz, "Intensity of frictional wear: GTAW treated castings of AK7 alloy", Archives of Foundry 2 (4), 414-419 (2002).

[21] A.W. Orłowicz and A. Trytek, "Solidification structure GTAWtreated iron castings", Archives of Foundry 2 (4), 192-197 (2002).

[22] D. Wenbin., J. Haiyan., Z. Xiaoqin., L. Dehui., and Y. Shoushan, "Microstructure and mechanical properties of GTA surface modified composite layer on magnesium alloy AZ31 with SiCp", Journal of Alloys and Compounds 429, 233-241 (2007).

[23] M. Szafarska, J. Iwaszko, M. Malik, and Sz. Tomczyński, "Surface modification of the AZ91 magnesium alloy", Archives of Civil and Mechanical Engineering 15, 854-861 (2015).
[24] M. Szafarska, J. Iwaszko, K. Kudła, and I. Łegowik, "Utilisation of high-energy heat sources in magnesium alloy surface layer treatment", Archives of Metallurgy and Materials 58 (2), 619-624 (2013).

[25] T. Zhu, Z.W. Chen, and W. Gao, "Incipient melting in partially melted zone during arc welding of AZ91D magnesium alloy", Materials Science and Engineering A 416, 246-252 (2006).

[26] T. Zhu, Z.W. Chen, and W. Gao, "Microstructure formation in partially melted zone during gas tungsten arc welding of AZ91 Mg cast sheet", Materials Characterization 59, 1550-1558 (2008).

[27] J. Shen, G. You, S. Long, and F. Pan, “Abnormal macropore formation during double-sided gas tungsten arc welding of magnesium AZ91D alloy", Materials Characterization 59, 1059-1065 (2008). 